\title{
Knowledge, Attitude, And Preventive Practice Towards COVID-19 Among Thai People Living With HIV/AIDS: An Online Survey
}

\author{
Natawan Khumsaen ${ }^{1 *}$, Supannee Peawnalaw ${ }^{2}$, Siritida Sripituk ${ }^{3}$, \\ Ausaniyaphon Chantorn ${ }^{4}$ \\ 1,2,3,4Boromarajonani College of Nursing, Suphanburi, 118 Moo 1, Sanamchai sub- \\ district, Muang district, Suphanburi province 72000, Thailand. \\ Email: knatawan@hotmail.com \\ ${ }^{*}$ Corresponding Author
}

\begin{abstract}
The study investigated knowledge, attitude, and preventive practice (KAP) concerning COVID-19 among Thai people living with HIV/AIDS (PLWHA). A cross-sectional online survey was conducted in January 2021. Google forms were used and shared through Line application. A set of KAP questionnaires was used to collect data. Results were analyzed using SPSS software.A total of 204 participants reported that they had a good knowledge; and possessed a positive attitude towards COVID-19. They were confident that Thailand can win the battle against COVID-19; and COVID-19 will be successfully controlled. For preventive behaviors, participants wore a face mask when leaving home and avoided crowded places. PLWHA who are on ART $<1$ year scored significantly higher as compared to both PLWHA who are on ART 1-5 years and who are on ART>5 years. About $26 \%$ of the participants reported television as the most commonly source of information on COVID-19. Our findings are valuable in informing nurses to plan an effective communication campaign by incorporating KAP regarding COVID-19 as modifying factors.
\end{abstract}

Keywords: COVID-19, HIV/AIDS, knowledge, attitude, practice

\section{Introduction}

Thailand was one of the Asian countries hit hardest by the HIV/AIDS epidemic since the late 1980s. HIV/AIDS epidemic has become a public health concern and has globally affected 38 million people, 690,000 of them dying from AIDS-related illness [1]. In 2019, nearly 6 million people were living with HIV (PLWHA) in Asia and Pacific region. It has been clear that the Asia and Pacific region is falling behind regions in Africa in its HIV response. In 2019, approximately 160,000 people died due to an AIDS-related illness in Asia and Pacific region [2]. In Thailand, a generalized HIV epidemic trajectory appears to be increasing, and as of 2019, there were 470,000 PLWH in Thailand and there were 14,000 AIDS-related deaths [3].

During a global and local effort to end HIV epidemic, the novel coronavirus disease-2019 (COVID-19) has emerged. As a result, as of June 24, 2021, there were $179,928,730$ cases of COVID-19 in over 200 countries and $3,898,531$ deaths with a $2.17 \%$ case fatality rate [4]. (Johns Hopkins University of Medicine, 2021). As of June 24, 2021, Thailand had 232,647 cases of COVID19 , and 1,775 deaths with a $0.76 \%$ case fatality rate. The median age of those infected was 40.75 years ( 1 month-97 years). Majority of the infected cases were of working age (31-49 years) population, with $75.01 \%$ females, and $38.86 \%$ living with diseases such as hypertension, diabetes, and cardiovascular disease [5].

To control the spread of COVID-19, Thailand has set up the Center for Covid-19 Situation Administration (CCSA) to manage and work with related sectors from the society. To get collaboration, the CCSA daily communicates with Thai people via Thai television channels and report COVID-19 situation in Thailand [6]. The CCSA has advised the public to seriously take DMHTT precautions to prevent COVID-19. Those DMHTT alphabets stand for Distancing, Mask wearing, Hand washing, Temperature checking, and Thai Chana application usage. The Thai government is also urging Thai people to avoid public gatherings and stay at home except for emergency reasons [7]. Considering the threat of COVID-19 super spread in Thailand, the Thai Ministry of Public Health (MOPH) has initiated surveillance at public and private hospitals across the country. Subsequently, the Thai government has announced a country-wide lockdown and came into effect since March 26, 2020, which are contributing largely to all aspects of Thai society including healthcare services.

Compared to other populations, PLWHA are considered as a high-risk vulnerable population for developing complications attributed to COVID-19 infection [8]. It 
has been reported that among patients with coinfection of HIV and COVID-19, there is a high prevalence of comorbidities, particularly those with underlying health conditions (i.e., hypertension, diabetes, and chronic kidney disease), or lower CD4 count [9-11]. This highlights the need to enhance the knowledge, attitudes, and practice (KAP) of PLWHA to protect this vulnerable group against COVID-19. Previous research conducted among PLWHA in Rwanda demonstrated that among the participants, 97\% possessed a high knowledge score. Meanwhile, 26\% reported pessimistic attitude, and most of them (90\%) practiced appropriate preventive practices on COVID19 [12]. It is worth emphasizing that the national lockdown during COVID-19 pandemic in Thailand has yielded an unprecedented negative impact on HIV care and treatment services [8]. Hence, it is important to understand the knowledge, attitude, and practice behaviors among PLWHA towards COVID-19.

Currently, many studies on KAP regarding COVID-19 have been carried out worldwide in general population, while literature addressed the KAP of PLWHA towards COVID-19 is limited. Thus, the current study aimed to investigate the knowledge, attitude, and preventive practice towards COVID-19 among Thai PLWHA.

\section{Materials And Methods}

\section{Study Design and Population}

A cross-sectional survey was conducted from January 1-31, 2021, among Thai PLWHA through a web-based survey because it was not feasible to do a clinic-based sampling survey during the government- imposed lockdown in Thailand. A simple random sampling technique was used to recruit participants who have accessed to an antiretroviral therapy (ART) clinic located in Dermbangnangbuach hospital, Suphanburi province, Thailand. The inclusion criteria included male and female Thai PLWHA who were: (a) 18 years or older; (b) understanding the study purpose; (c) a social media user; and (d) willing to voluntarily participate in this study. Employing power analysis using the $G^{*}$ power program [13] for sample size calculation, effect size of 0.20 , alpha of 0.05 , and power of test as 0.80 determined that a sample size of 191 would be sufficient. Nonetheless, 204 participants completed the survey questionnaires, and were taken for final analysis.

\section{Data Collection Procedure}

Data collection was performed via a structure questionnaire. This was developed using Google survey tool (Google Forms), with a consent form attached to it. A link of the set of online questionnaires was sent through the networks of the researchers via Line application, the most popular and mostly used social media in Thailand, to the participants of the study. Upon receiving and clicking the link, the participants were automatically and directly leading to the study information and informed consent. After agreeing to take the online survey, they filled up their demographic information. Then, a set of online questionnaires consecutively appeared, which the participants were supposed to answer and completed them all. Since this was the online survey study, so that only the participants with access to the internet either on their smart phones or home use internet would be able to participate in the study.

\section{Measurements}

The survey instrument employed in the study was initially developed in English by Zhong and colleagues [14] consisting of KAP towards COVID-19. Then, the instrument was translated into Thai language by the authors and then translated back into English by two bilingual experts who are fluent in both Thai and English to ensure translation accuracy. Next, the questionnaire was validated in a pilot of 30 participants prior to data collection of the current study. The final questionnaire used in this study contained questions assessing socio-demographics (gender, age-group, marital status, education, occupation, monthly income, and time on ART), KAP towards COVID-19. The KAP questionnaire contains 16 items consisting of 3 distinct subscales: knowledge (e.g., The main clinical symptoms of COVID-19 are fever, fatigue, dry cough, and myalgia), attitude (e.g., Do you agree that COVID-19 will finally be successfully controlled?), and preventive practice towards COVID19 (e.g., In recent days, have you worn a face mask when leaving home?). A COVID-19 knowledge subscale had 12 questions (K1-K12): 4 regarding clinical presentations, 3 regarding transmission routes, and 5 regarding prevention and control of COVID-19. The items on the scale were arranged in a three-category response format (true, false, and do not know). Each correct response was given a point value of 1 . The do not know responses were not assigned a value. The total knowledge score was computed from the correct responses ranging from 0 to 12 , with a higher score indicating greater COVID-19 knowledge. In the second subscale, we evaluated attitude towards COVID-19 using 2 questions (A1-A2) regarding the agreement on the final control of COVID-19 and the confidence in winning the battle against COVID-19. In the third subscale, we assessed practices towards COVID-19 using 2 items (P1-P2): going to a crowed place and wearing a face mask when going out in recent days. The KAP towards COVID-19 scale-Thai version has been shown to be reliable and valid; the Cronbach's alpha coefficient of this scale was 0.81 , indicating acceptable internal consistency [15].

\section{Data Management and Statistical Analysis}

Data was captured electronically on an excel sheet. Then, Statistical Package for the Social Sciences (SPSS version 23.0 for Windows) was used to analyze data. Descriptive statistics (mean, standard deviation, 
percentage, and frequency distribution) were performed to describe the sample.

The differences between duration of ART on KAP were assessed using one-way analysis of variance (ANOVA) test. All statistical tests were two-tailed, and a statistical significance value was set at $p<0.05$.

\section{Ethical Considerations}

This study was approved by the Institutional Review Board of Boromarajonani College of Nursing, Suphanburi, Thailand (approval number: EC045/2563). Electronic consent was provided before completing the survey.

\section{Results}

\section{Participant characteristics}

Data presented in Table 1 showed that 204 PLWHA completed the survey and 108 (52.9\%) were male. The majority $(60.3 \%)$ of the participants were between 30 49 years of age. Almost $60 \%$ were single, and $55.4 \%$ finished primary school. The majority $(61.3 \%)$ of them reported to be service workers. More than half of the participants reported monthly income less than 5,000 Thai Baht, and almost 57\% reported having been on ART for more than 5 years.

\begin{tabular}{|c|c|c|}
\hline c & $\mathbf{N}$ & (\%) \\
\hline \multicolumn{3}{|l|}{ Gender } \\
\hline Male & 108 & 52.9 \\
\hline Female & 96 & 47.1 \\
\hline \multicolumn{3}{|l|}{ Age (in years) } \\
\hline $18-29$ & 13 & 6.4 \\
\hline $30-49$ & 123 & 60.3 \\
\hline $50-59$ & 50 & 24.5 \\
\hline $\begin{array}{l}\geq 60 \\
\text { Marital status }\end{array}$ & 18 & 8.8 \\
\hline Single & 122 & 59.8 \\
\hline Married & 77 & 37.7 \\
\hline $\begin{array}{l}\text { Others (divorced, separated, and widowed) } \\
\text { Education }\end{array}$ & 5 & 2.5 \\
\hline Primary school & 113 & 55.4 \\
\hline Secondary school & 59 & 28.9 \\
\hline High school & 11 & 5.4 \\
\hline Vocational school & 4 & 2.0 \\
\hline Diploma & 5 & 2.5 \\
\hline Bachelor & 12 & 5.9 \\
\hline \multicolumn{3}{|l|}{ Occupation } \\
\hline Government officer & 3 & 1.5 \\
\hline State enterprise employee & 1 & 0.5 \\
\hline Merchant & 35 & 17.2 \\
\hline Agriculturist & 23 & 11.3 \\
\hline Service workers & 125 & 61.3 \\
\hline Others & 17 & 8.3 \\
\hline \multicolumn{3}{|l|}{ Monthly income (in Bahts, 32 Bahts=USD \$1) } \\
\hline$<5,000$ & 108 & 52.9 \\
\hline $5,001-10,000$ & 62 & 30.4 \\
\hline $10,001-20,000$ & 22 & 10.8 \\
\hline $20,001-30,000$ & 8 & 3.9 \\
\hline$>30,000$ & 4 & 2.0 \\
\hline \multicolumn{3}{|l|}{ Duration on ART (in years) } \\
\hline$<1$ & 28 & 13.7 \\
\hline $1-5$ & 60 & 29.4 \\
\hline$>5$ & 116 & 56.9 \\
\hline
\end{tabular}

Distribution of knowledge, attitude, and preventive practice towards COVID-19

Table 2 showed the descriptive analysis of KAP score. The correct answer rates of the 12 questions on the COVID-19 knowledge questionnaire were 86.8-98\%. The overall mean knowledge score was 11.38 (SD. $=1.53$; range $=0-12$ ), suggesting an overall $94.83 \%$ $(11.38 / 12 * 100)$ correct rate on this knowledge test. The majority $(98 \%)$ of the participants knew that isolation and treatment of people who are infected with the COVID-19 virus are effective ways to reduce the spread of the virus. Most participants
98.0\%) also knew that there currently is no effective cure for COVID-2019, but early symptomatic and supportive treatment can help most patients recover from the infection. The overall mean attitude score of the participants was 1.69 (SD.=0.69). About $82.4 \%$ agreed that COVID-19 will finally be successfully controlled; and $85.3 \%$ of them were confident that Thailand can win the battle against COVID-19. The overall mean preventive practice score was 1.72 (SD.=1.83). Most participants had not gone to any crowded place $(82.8 \%)$ and wore a mask when leaving home $(99.5 \%)$ in recent days. 
Table 2: Distribution of knowledge, attitude, and preventive practice towards COVID-19 scores $(n=204)$

\section{Variable}

Knowledge (K)

K1. The main clinical symptoms of COVID-19 are fever, fatigue, dry cough, and myalgia

K2. Unlike the common cold, stuffy nose, runny nose, and sneezing are less common in

persons infected with the COVID-19 virus.

K3. There currently is no effective cure for COVID-2019, but early symptomatic and

supportive treatment can help most patients recover from the infection.

K4. Not all persons with COVID-2019 will develop to severe cases. Only those who are

elderly, have chronic illnesses, and are obese are more likely to be severe cases.

K5. Eating or contacting wild animals would result in the infection by the COVID-19 virus.

K6. Persons with COVID-2019 cannot infect the virus to others when a fever is not present.

K7. The COVID-19 virus spreads via respiratory droplets of infected individuals.

K8. Ordinary residents can wear general medical masks to prevent the infection by the

COVID-19 virus.

$\mathrm{K} 9$. It is not necessary for children and young adults to take measures to prevent the infection by the COVID-19 virus.

K10. To prevent the infection by COVID-19, individuals should avoid going to crowded

places such as train stations and avoid taking public transportations.

K11. Isolation and treatment of people who are infected with the COVID-19 virus are

effective ways to reduce the spread of the virus.

K12. People who have contact with someone infected with the COVID-19 virus should be

immediately isolated in a proper place. In general, the observation period is 14 days.

Total knowledge score

Attitude (A)

A1. Do you agree that COVID-19 will finally be successfully controlled?

A2. Do you have confidence that Thailand can win the battle against the COVID-19 virus?

Total attitude score

Practice $(\mathrm{P})$

$\mathrm{P} 1$. In recent days, have you gone to any crowded place?

P2. In recent days, have you worn a mask when leaving home?

Total practice score

\begin{tabular}{|c|c|c|c|c|}
\hline Mean & SD. & correct $^{a}$ & Incorrect $^{a}$ & \\
\hline 0.91 & 0.29 & $185(90.7)$ & 19(9.3) & \\
\hline 0.92 & 0.27 & $188(92.2)$ & $16(7.8)$ & \\
\hline 0.98 & 0.14 & $200(98.0)$ & $4(2.0)$ & \\
\hline 0.91 & 0.28 & $186(91.2)$ & $18(8.8)$ & \\
\hline 0.92 & 0.27 & $188(92.2)$ & $16(7.8)$ & \\
\hline 0.88 & 0.32 & $180(88.2)$ & $24(11.8)$ & \\
\hline 0.96 & 0.19 & $196(96.1)$ & $8(3.9)$ & \\
\hline 0.98 & 0.15 & $199(97.5)$ & $5(2.5)$ & \\
\hline 0.87 & 0.34 & $177(86.8)$ & $27(13.2)$ & \\
\hline 0.94 & 0.24 & 192(94.1) & $12(5.9)$ & \\
\hline 0.98 & 0.14 & $200(98.0)$ & $4(2.0)$ & \\
\hline 0.98 & 0.15 & 199(97.5) & $5(2.5)$ & \\
\hline \multicolumn{5}{|l|}{$11.38(1.54)^{b}$} \\
\hline $\begin{array}{l}\text { Mean } \\
0.82\end{array}$ & $\begin{array}{l}\text { SD. } \\
0.38\end{array}$ & $\begin{array}{l}\text { Agree }^{a} \\
168(82.4)\end{array}$ & $\begin{array}{l}\text { Disagree }^{a} \\
36(17.6)\end{array}$ & $\begin{array}{l}\text { Don't knowa } \\
0(0)\end{array}$ \\
\hline & & $Y_{e s}^{a}$ & Noa & \\
\hline $\begin{array}{l}0.85 \\
1.69(0.69)^{b}\end{array}$ & 0.35 & 174(85.3) & $30(14.7)$ & \\
\hline Mean & SD. & $Y_{e s}^{a}$ & $\mathrm{No}^{\mathrm{a}}$ & \\
\hline 0.17 & 0.38 & $\begin{array}{l}35(17.2) \\
Y^{a} s^{a}\end{array}$ & $\begin{array}{l}169(82.8) \\
\mathrm{No}^{\mathrm{a}}\end{array}$ & \\
\hline $\begin{array}{l}1.00 \\
1.72(1.83)^{b}\end{array}$ & 0.07 & 203(99.5) & $1(0.5)$ & \\
\hline
\end{tabular}

${ }^{\mathrm{a}} \mathrm{n}(\%) ;{ }^{\mathrm{b}}$ mean(standard deviation) 
The differences among scores of KAP towards COVID-19 in relation to duration on ART

Regarding preventive practice towards COVID-19, PLWHA who are on ART for less than 1 year scored significantly higher $(\mathrm{p}<0.05)$ as compared to both PLWHA who are on ART for 1-5 years and PLWHA who are on ART for more than 5 years, as shown in Table 3.

Table 3: One-way ANOVA test comparing scores of KAP towards COVID-19 in relation to duration on ART

$\begin{array}{llllll}\text { Domains } & \text { Mean (SD.) } & & & & \\ & \text { On ART }<\text { 1 year } & \text { On ART 1-5 years } & \text { On ART }>5 \text { years } & \text { F } & \text { p-value } \\ \text { Knowledge } & 11.500(1.374) & 11.383(1.366) & 11.353(1.664) & 0.102 & 0.90 \\ \text { Attitude } & 1.642(0.780) & 1.750(0.600) & 1.663(0.694) & 0.366 & 0.79 \\ \text { Preventive practice } & 2.428(2.767) & 1.350(0.798) & 1.741(1.902) & 3.396 & 0.03^{\star}\end{array}$

${ }^{*} \mathrm{p}<0.05$ level

\section{Sources of information towards COVID-19}

Approximately $25.5 \%(n=52)$ of participants reported television (TV) as the most commonly source of information towards COVID-19 and the least commonly source was newspaper/magazine $(6.9 \%)(n=28)$. Figure 1 illustrates total percentages for each source.

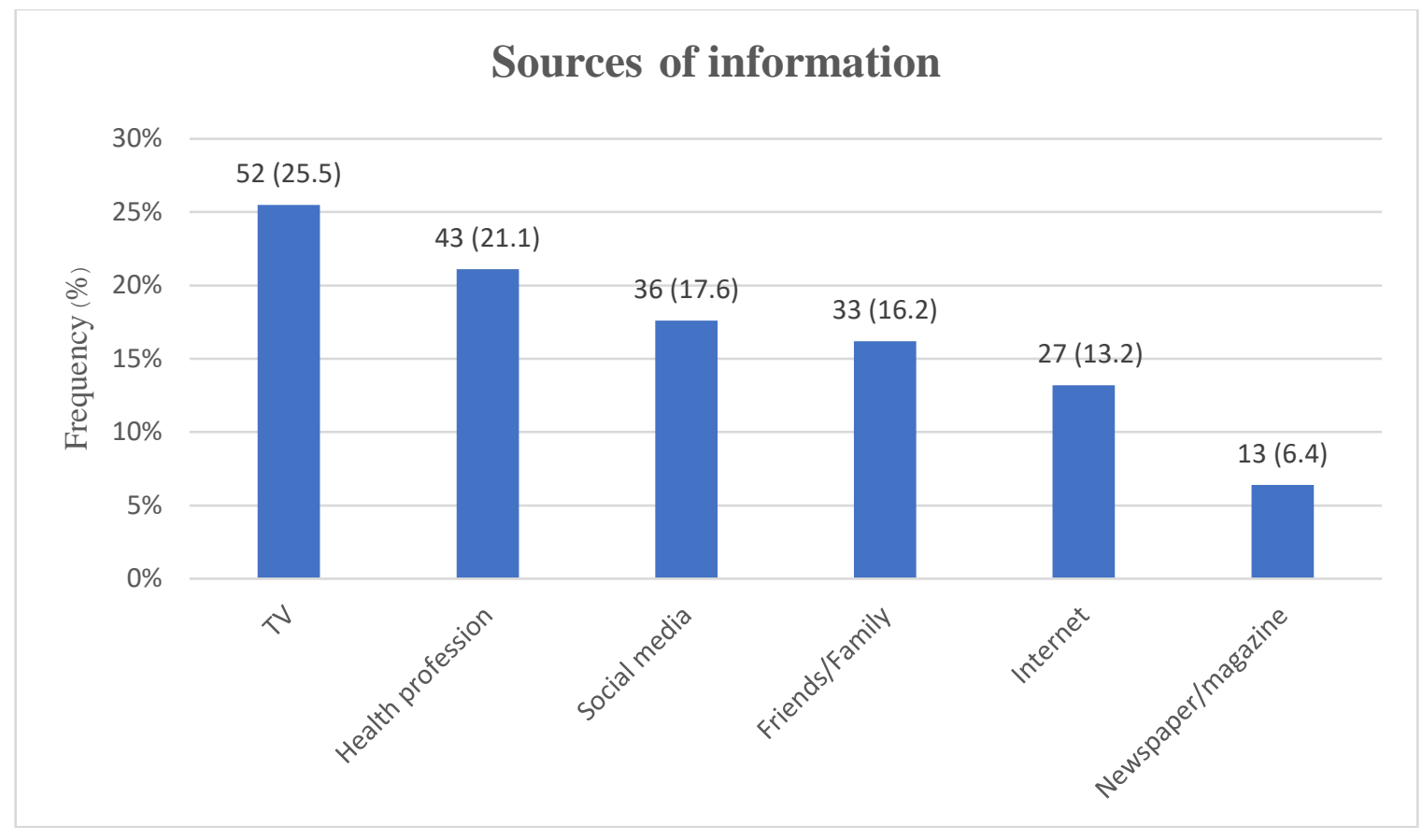

\section{Discussion}

Currently, COVID-19 outbreak has dramatically changed people's lives. With the scarce literature on COVID-19 at the beginning of its pandemic, information has gradually been updated and shifting over time with the amount of increased research. Nonetheless, there is a few research to understand knowledge, attitude, and preventive practices toward COVID-19 in PLWHA. The findings of this study may inform health policy makers to formulate and implement response plans to tackle with COVID-19 pandemic.

Our findings demonstrated the average knowledge score was at $94.83 \%$, which is quite good knowledge of COVID-19. This finding is congruent with the study conducted among PLWHA in ART clinic located in Kigali, Rwanda which found that most of the participants reported a high knowledge score regarding COVID-19 [12]. Moreover, compared to the study conducted in general population of Thailand, our participants scored greater in term of their COVID-19 knowledge compared to the participants in the study done in northern Thailand during the early period of the pandemic [16]. One explanation is that this study was conducted at the later stage of COVID19 pandemic. The Thai government and media had heavily emphasized more on the prevention of COVID19 infection during our data collection period. Health information could be easily accessed online, improving knowledge on COVID-19 among the participants [17]. We also found that the most common information sources for participants on COVID-19 were from TV, followed by health professions, which is where their COVID-19 knowledge is based off. These findings were congruent with other studies done in Malaysia, India, and US where television and health professionals were found to be the primary information sources of COVID-19 [18-20].

Regarding attitude towards COVID-19, the average score was at $84.5 \%$. our study showed that most 
participants expressed positive attitude towards COVID-19 pandemic. Compared to the recent study conducted among PLWHA in Rwanda [12] and India [21], our findings showed a better attitude score. Positive attitude of COVID-19 could be explained by perceptions of an effective response by the Thai government to the pandemic and an easy accessibility to healthcare services [22].

As for preventive practice, the average score was at $86 \%$. Despite the optimistic attitude, our participants seriously adhere to precautionary measures to prevent COVID-19 infection such as not going to crowded places and wearing a mask when leaving home. This is inconsistent with other studies conducted in Rwanda [12], China [14], and Iran [23]. This might be explained by the easy accessibility and availability of COVID-19 prevention online, improving participants' knowledge and preventive practice [24].

Furthermore, there were significant differences in preventive practice behavior towards COVID-19 among PLWHA who are on ART for less than 1 year, PLWHA who are on ART for 1-5 years, and PLWHA who are on ART for more than 5 years. The reason for this could be that PLWHA on ART for less than a year were enrolled into the current study during the rise period of the COVID-19 outbreak and benefited from opportunistic health promotion [25]. However, this requires further attention by the healthcare staff to do extra session in health information regarding COVID-19. Our finding provides crucial insights for refocusing healthcare education program for PLWHA during COVID-19 outbreak.

Thus, to promote preventive practice behaviors, an effective starting point might be improving people's knowledge and fostering optimistic attitude towards COVID-19 prevention. According to the KAP model, knowledge is the basis and attitude is the driving force of behavior change [26].

Several limitations of the study should be noted. First, self-reported method was used to collect data so that this is prone to social desirability. Second, this study was conducted in only PLWHA in one setting, hence, this might not allow generalizability of the findings to other locations. Third, this study employed a crosssectional study design that cannot establish causal inferences. Lastly, this study employed an online survey with a convenience sample and collected data using Line application. Hence, Thai PLWHA participated in this study were only those with internet access. Despite the limitations, our findings provide empirical data for health professions. The current study is a worthwhile beginning to prevent COVID-19 transmission in the future. As there have been few studies done on KAP towards COVID-19 among PLWHA in Thailand, our study is one of the earliest studies to be conducted.

\section{Conclusion}

The main significance of this study was to provide preliminary evidence of KAP on COVID-19 observed from Thai PLWHA of Dermbangnangbuach hospital, Suphanburi province. Our study revealed that Thai PLWHA possessed adequate knowledge, demonstrated a positive attitude, and practiced appropriate preventive behaviors regarding COVID19. These findings could be used to inform public level on how to practice preventive behaviors during the outbreak. Moreover, these findings might be useful for Thai health professionals and health policy makers to develop effective practices and to modify health awareness campaigns on COVID-19.

\section{Acknowledgements}

The authors thank all PLWHA who participated in the study as well as the healthcare staff at ART clinic, Dermbangnangbuach hospital, Suphanburi province for their assistance in sample recruitment.

\section{Funding}

This study was financially supported by Boromarajonani College of Nursing, Suphanburi, Faculty of Nursing, Praboromarajanok Institute, Thailand.

\section{Conflicts Of Interest}

The authors declare that they have no conflict of interest.

\section{References}

1. World Health Organization (WHO). 2020. HIV/AIDS data and statistic. Retrieved from: https://www.who.int/hiv/data/en/ (Accessed November 27, 2020).

2. UNAIDS. 2019. Factsheet: global AIDS update. UNAIDS Geneva.

3. Global information and education on HIV and AIDS in Thailand. 2019. Retrieved from: https://www. avert.org/professionals/hiv-around-world/asiapacific/Thailand. (Accessed on November 30, 2020).

4. Johns Hopkins University of Medicine. 2021. Corona virus resource center. COVID-19 Dashboard by the Center for Systems Science and Engineering (CSSE) at Johns Hopkins University. Retrieved from: https://coronavirus.jhu.edu/map.html. (Accessed on June 24, 2021).

5. Department of Disease Control of Thailand. 2021. Covid19 Infected Situation Reports. Retrieved from: https://covid19.ddc.moph.go.th/en. (Accessed on June 24, 2021).

6. Ahn H-J, Rodkin PC. Classroom-level predictors of the social status of aggression: Friendship centralization, friendship density, teacher- student attunement, and 
gender. Journal of Educational Psychology. 2014;106(4):1144-1155.

7. Srisawat N, lamsirithaworn S, Tantawichiein T, Thisyakorn U. COVID-19: Lessons from Thailand. Ann Acad Med Singap. 2021;50(1):96-97.

8. Srichannil C. The COVID-19 pandemic and Thailand: A psychologist's viewpoint. Psychological Trauma: Theory, Research, Practice, and Policy. 2020;12(5):485-487.

9. Gatechompol S, Avihingsanon A, Putcharoen O, Ruxrungtham K, Kuritzkes DR. COVID-19 and HIV infection co-pandemics and their impact: a review of the literature. AIDS Res Ther. 2021;18(1):28.

10. Suwanwongse K, Shabarek N. Clinical features and outcome of HIV/SARS-CoV-2 coinfected patients in The Bronx, New York city. J Med Virol. 2020;92(11):23872389.

11. An application of a mixture of exponential distributions for assessing hazard rates from COVID-19 2020) Journal of Population Therapeutics and Clinical Pharmacology, 27 (Special Issue 1), pp. e58-e63.

12. Shalev N, Scherer M, LaSota ED, Antoniou P, Yin MT, Zucker J, et al. Clinical Characteristics and Outcomes in People Living with Human Immunodeficiency Virus Hospitalized for Coronavirus Disease 2019. Clinical Infectious Diseases. 2020;71(16):2294-2297.

13. Zhou F, Yu T, Du R, Fan G, Liu Y, Liu Z, et al. Clinical course and risk factors for mortality of adult inpatients with COVID-19 in Wuhan, China: a retrospective cohort study. The Lancet. 2020;395(10229):1054-1062.

14. Iradukunda PG, Pierre G, Muhozi V, Denhere K, Dzinamarira T. Knowledge, Attitude, and Practice Towards COVID-19 Among People Living with HIV/AIDS in Kigali, Rwanda. J Community Health. 2021;46(2):245250.

15. Faul F, Erdfelder E, Lang A, Buchner A. G*Power 3: A flexible statistical power analysis program for the social, behavioral, and biomedical sciences. Behavior Research Methods. 2007;39(2):175-191.

16. Zhong B, Luo W, Li H, Zhang Q, Liu X, Li W, et al. Knowledge, attitudes, and practices towards COVID-19 among Chinese residents during the rapid rise period of the COVID-19 outbreak: a quick online cross-sectional survey. Int J Biol Sci. 2020;16(10):1745-1752.

17. Taber KS. The Use of Cronbach's Alpha When Developing and Reporting Research Instruments in Science Education. Res Sci Educ. 2018;48(6):1273-96.

18. Srichan P, Apidechkul T, Tamornpark R, Yeemard F, Khunthason S, Kitchanapaiboon S, et al. Knowledge, attitudes and preparedness to respond to COVID-19 among the border population of northern Thailand in the early period of the pandemic: a cross-sectional study. WHO South-East Asia J Public Health. 2020;9(2):118-125.
19. Abdulai A, Tiffere A, Adam F, Kabanunye MM. COVID-19 information-related digital literacy among online health consumers in a low-income country. International Journal of Medical Informatics. 2021;145:104322.

20. Mohamad E, Tham JS, Ayub SH, Hamzah MR, Hashim H, Azlan AA. Relationship Between COVID-19 Information Sources and Attitudes in Battling the Pandemic Among the Malaysian Public: Cross-Sectional Survey Study. J Med Internet Res. 2020;22(11):e23922.

21. Paul G, Sharma S, Singh G, Singh G, Sharma S, Paul BS, et al. Assessment of knowledge gaps and perceptions about COVID-19 among health care workers and general public-national cross-sectional study. J Anaesthesiol Clin Pharmacol. 2020 ;36(3):337-344.

22. Shafiq M, Elharake JA, Malik AA, McFadden SM, Aguolu OG, Omer SB. COVID-19 Sources of Information, Knowledge, and Preventive Behaviors Among the US Adult Population. J Public Health Manag Pract. 2021;27(3):278-284.

23. Ghate MV, Shidhaye PR, Gadhe KR, Gurav SG, Deoraj P. Knowledge, attitude and practices towards COVID-19 among people living with HIV in Pune, India: a crosssectional study. Int J Res Med Sci. 2021;9(5):1458-1465.

24. Nittayasoot N, Suphanchaimat R, Namwat C, Dejburum $\mathrm{P}$, Tangcharoensathien $\mathrm{V}$. Public health policies and health-care workers' response to the COVID-19 pandemic, Thailand. Bull World Health Organ. 2021;99(4):312-318.

25. Taghrir MH, Borazjani R, Shiraly R. COVID-19 and Iranian Medical Students; A Survey on Their Related-Knowledge, Preventive Behaviors and Risk Perception. Arch Iran Med. 2020;23(4):249-254.

26. Estacio EV, Whittle R, Protheroe J. The digital divide: Examining socio-demographic factors associated with health literacy, access and use of internet to seek health information. J Health Psychol. 2019;24(12):1668-1675.

27. Spanou C, Simpson SA, Hood K, Edwards A, Cohen D, Rollnick $S$, et al. Preventing disease through opportunistic, rapid engagement by primary care teams using behaviour change counselling (PRE-EMPT): protocol for a general practice-based cluster randomised trial. BMC Fam Pract. 2010;11(69):1-10.

28. Li WY, Liu J, Yu GL, Xu JH. Application of the knowledgebelief-practice model in nursing practice: current status and prospects. J Nurs Sci. 2015;30(6):107-110. 